\title{
Life-history parameters of Encarsia formosa, Eretmocerus eremicus and $E$. mundus, aphelinid parasitoids of Bemisia argentifolii (Hemiptera: Aleyrodidae)
}

\author{
Yu Tong QIU, Joop C. VAN LENTEREN, Yvonne C. DROST and ConNIE J.A.M. POSTHUMA-DOODEMAN \\ Laboratory of Entomology, Wageningen University; P.O.Box 8031, 6700 EH Wageningen, The Netherlands \\ e-mails: yu.tongqiu@wur.nl; Joop.vanLenteren@wur.nl
}

Key words. Hymenoptera, Aphelinidae, Homoptera, Aleyrodidae, whiteflies, Encarsia formosa, Eretmocerus eremicus, Eretmocerus mundus, biological control, life history, longevity, development time

\begin{abstract}
Life-history parameters (juvenile development time, adult longevity, host instar preference and rate of parasitism) of four parasitoids of Bemisia argentifolii (two strains of Encarsia formosa (D and B), Eretmocerus eremicus and Eretmocerus mundus) were studied in the laboratory. At $15^{\circ} \mathrm{C}$ juvenile development time was the shortest for $E$. formosa B ( 48 days), longest for $E$. eremicus (79.3 days) and intermediate for E. formosa D (62.8 days) and E. mundus (64 days) at $15^{\circ} \mathrm{C}$. With increase in temperature, development time decreased to around 14 days for all species/strains at $32^{\circ} \mathrm{C}$. The lower developmental threshold for development was $11.5,8.1,13.0$ and $11.5^{\circ} \mathrm{C}$ for E. formosa D, E. formosa B, E. eremicus and E. mundus, respectively. E. formosa D and B, and E. mundus all appeared to prefer to parasitize $3^{\text {rd }}$ instar nymphs. The presence of hosts shortened adult longevity in most of the parasitoids, with the exception of E. formosa B, which lived longer than other species/strains irrespective of the presence of hosts. At $15^{\circ} \mathrm{C}$ daily parasitism was very low by all parasitoids. The two Encarsia strains had a constant, but low rate of reproduction during adult life, while the two Eretmocerus species had a very high rate of reproduction when one-day old, which then decreased very quickly. Lifetime fecundity, estimated using a non-linear model, indicated that it was higher for the two Encarsia strains than for the Eretmocerus species. Life history parameters reported in the literature for the four parasitoids are reviewed and compared with our results. Finally, the potential value for the biological control of whiteflies on greenhouse crops of parasitoids having either a high reproductive rate over a short period (Eretmocerus spp.) or a low rate of reproduction over a long period (Encarsia spp.) is discussed.
\end{abstract}

\section{INTRODUCTION}

Bemisia tabaci (Gennadius) (Hemiptera: Aleyrodidae) was first described in 1889 as a potential pest of tobacco in Greece (Gennadius, 1889). It was frequently reported as a pest of field crops, like bean and cotton (Brown et al., 1995), and causing serious damage to poinsettia in greenhouses in Florida (Price, 1987). Bemisia then spread all over the United States damaging a range of field crops, vegetables and ornamental plants. It was accidentally imported into Europe around 1987 (Fransen, 1994) and became a serious pest of crops in greenhouses. In the past two decades the pest has invaded all continents, which has resulted in research into ways of controlling this pest. The species was first designated as the "B" strain of $B$. tabaci, and later on identified as a new species, $B$. argentifolii (Bellows et al., 1994). However, the taxonomy of this pest remains confused and controversial (Naranjo \& Ellsworth, 2001), and we refer to Perring (2001) for a recent discussion of the Bemisia tabaci species complex. Bemisia causes direct feeding damage, vectors a number of devastating plant viruses, reduces the quality of the harvested product as a result of the excretion of honeydew, and can be the source of various other problems (Drost et al., 1998).

At present, management of $B$. argentifolii depends mainly on chemical control but as this species is resistant to many insecticides, chemical control is difficult and resistance management is of high priority (Costa et al.,
1993; Cahill et al., 1996; Palumbo et al., 2001). Also, chemical pesticides interfer with biological pest control, which is now the main means of pest control in modern greenhouses (van Lenteren, 2000). In addition, chemical control may create problems for human health and the environment. So there is an urgent need for more sustainable, more effective and environmentally friendlier methods of control.

During the past decades, much research was directed at finding efficient natural enemies of whiteflies, in particular of $B$. argentifollii (for overviews, see Gerling 1990; Gerling \& Mayer, 1995; Gerling et al., 2001). According to Naranjo (2001) about 1500 papers on the biological control of Bemisia appeared between 1984 and the end of 2000. Between the end of 2000 and March 2003, we estimate that another 270 papers were published on natural enemies of whitefly. Most of the papers published since the start of 2000 concern whitefly parasitoids of the genera Encarsia (circa 125; e.g. DeBarro et al., 2000), Eretmocerus (circa 45; e.g. Drost et al., 2000) and Amitus (circa 15; e.g. Manzano et al., 2000; de Vis et al., 2003), about 70 on various groups of predators (e.g. Gerling et al., 2001), and several (circa 15) on entomopathogenic fungi (e.g. Faria \& Wright, 2001; Meekes et al., 2002). Despite all these publications on the biological control of Bemisia, Naranjo \& Ellsworth (2001) conclude that: "biological control of $B$. tabaci by parasitoids, predators and fungi represents a key strategy whose potential has gone largely unrealized in many affected 
cropping systems throughout the world." Gerling et al. (2001) when reviewing parasitoids and predators of Bemisia, state: "Although certain natural enemies have proven effective components in B. tabaci control, there are still unexplored, potentially valuable species in many areas of the world.", and also: "The listed fauna of $B$. tabaci parasitoids is extensive, but relatively few have been studied or are intentionally used for pest control." In our view many whitefly biological control projects were opportunistic, terminated prematurely and often even without publishing the results. As such projects contribute negatively to the image of biological control, our philosophy is to do long-term, pure scientific and applied research on whiteflies (e.g. van Lenteren \& Noldus, 1990) and parasitoids (e.g. van Lenteren et al., 1996).

Our research group has for the past 25 years been working on the biological control of greenhouse pests, initially mainly on parastioids of greenhouse whitefly (Trialeurodes vaporariorum (Westwood), van Lenteren et al., 1996) and during the past 15 years also on parasitoids of Bemisia (van Lenteren et al., 1997; Drost et al., 2000). For B. tabaci, Gerling et al. (2001) list 34 species of Encarsia, 12 species of Eretmocerus, one species of Signiphora and Methycus, and two Amitus species. These authors conclude that: "with the exception of E. formosa ... and despite the frequent use of Encarsia species, data on their biological and taxonomic characteristics remain deficient even for commonly used species." Even less is known about other parasitoid genera, although recently the biology of Eretmocerus and Amitus have received some attention (see below).

Over the last 30 years the seasonal inoculative releases of Encarsia formosa Gahan (Hymenoptera: Aphelinidae) to control greenhouse whitefly, Trialeurodes vaporariorum Westwood (Hemiptera: Aleyrodidae) in greenhouses have been commercially very successful (van Lenteren \& Woets, 1988; Gerling et al., 2001). However, $B$. argentifolii is a less favourable host for the E. formosa strain that is mass produced in the Netherlands, and control with $E$. formosa in greenhouses is not successful at high release rates of 4-7 adult females per plant per week in North America (Hoddle \& van Driesche, 1996). As a strain of E. formosa collected in Maryland, USA (the so called Beltsville strain) was considered to be a more promising agent for $B$. argentifolii control, according to laboratory and greenhouse evaluation (Heinz \& Parrella, 1994; van Lenteren \& Brasch, 1994; Hoddle et al., 1997; van Lenteren et al., 1997), it was included in the current study, together with the Dutch E. formosa strain for comparison. Field studies showed that in North America Eretmocerus species are the most abundant parasitoids (Goolsby et al., 1998) of B. argentifoliii. Further, inundative releases of Eretmocerus eremicus Rose and Zolnerowich (Hymenoptera: Aphelinidae) in greenhouses reduce $B$. argentifolii populations substantially (Hoddle et al., 1998). As in Europe Eretmocerus mundus often spontaneously entered greenhouses and attacked Bemisia, we included E. eremicus and E. mundus Mercet (Hymenoptera: Aphelinidae) in our study. We also studied the para- sitoid Amitus bennetti Viggiani and Evans (Hymenoptera: Aphelinidae), because it has a different reproduction strategy (Drost et al.,1999). Encarsia and Eretmocerus are synovigenic and exhibit host feeding, whereas Amitus is proovigenic. We have recently published behavioural data on these 4 species of parasitoids (Drost et al., 1998, 1999, 2000).

Although there are plenty of published data on the life history parameters of whitefly parasitoids, few were obtained under the same experimental conditions (whitefly species, host plant species, confusion over the taxonomic status of parasitoid species and temperature etc.). Therefore it is very difficult to compare between these data. In this study we investigated the life-history parameters of four aphelinid parasitoids of $B$. argentifolii using the same experimental protocol. Analyses of the differences in parameter values can help us predict the relative capacity of these parasitoids to control $B$. argentifolii at different temperatures. In addition, the potential value for the biological control of whiteflies on greenhouse crops of parasitoids, having either a high reproductive rate over a short period (Amitus and Eretmocerus spp.) or a low rate of reproduction over a long period (Encarsia spp.), is discussed.

\section{MATERIALS AND METHODS}

\section{Origin of whitefly and parasitoid species/strains}

Bemisia argentifolii originated from a population that entered the Netherlands on poinsettia cuttings from California in 1989 (Fransen, 1994) and has been reared on poinsettia (cultivar Goldfinger) in the Laboratory of Entomology, Wageningen, since 1995.

Encarsia formosa D (the Dutch strain of Encarsia formosa) pupae were obtained from Koppert Biological Systems Inc.,The Netherlands. They have been reared on $T$. vaporariorum on tobacco for more than 20 years. Adults that emerged from the pupae were used directly in the experiments.

Encarsia formosa B (the Maryland strain of E. formosa) was collected from T. vaporariorum in Maryland, USA, and subsequently reared on $B$. argentifolii on poinsettia for more than nine years, and is referred to as the Beltsville strain (Bentz, 1996). A starting colony was received from J. P. Sanderson at Cornell University in 1995, since when it has been cultured in the Laboratory of Entomology, Wageningen.

Eretmocerus eremicus, formerly named E. nr. californicus, pupae were from Koppert Biological Systems Inc., The Netherlands. The species originated from Arizona, USA and has been reared on T. vaporariorum on tobacco since 1995. Adults that emerged from the pupae were used directly in the experiments.

Eretmocerus mundus pupae were obtained from Bioplanet, Cesena, Italy, where the parasitoid was reared on $B$. tabaci (unknown biotype) on courgette. E. mundus was reared on $B$. argentifolii on poinsettia since 1995 in the Laboratory of Entomology, Wageningen.

\section{Rearing procedures}

Colonies of $B$. argentifolii were maintained by infesting poinsettia plants with whitefly adults for three days in cages $(50 \mathrm{~cm}$ $\times 50 \mathrm{~cm} \times 56 \mathrm{~cm}$ ) and subsequently keeping the infected plants, without whitefly adults, in separate cages. In this way a continuous supply of plants with the desired nymphal stages for the parasitoid cultures or for the whitefly culture was maintained. The whitefly culture was maintained in a greenhouse at $26 \pm$ 
$1{ }^{\circ} \mathrm{C}$ and $70 \%$ R.H. with a $16 \mathrm{~L}: 8 \mathrm{D}$ h photoperiod. Colonies of $E$. formosa (MD) and E. mundus were established using poinsettia plants infested with third and/or fourth instar nymphs of $B$. argentifolii. About 150 parasitized pupae per parasitoid species were left to emerge in cages $(40 \mathrm{~cm} \times 40 \mathrm{~cm} \times 30 \mathrm{~cm})$ containing a poinsettia plant infested with whitefly nymphs. By starting every new colony with pupae and keeping cultures of different species of the same genus in different rooms, contamination of parasitoid cultures by other parasitoid species was prevented. All parasitoid cultures were kept at $25 \pm 1{ }^{\circ} \mathrm{C}$ and $60 \%$ R.H. with a 16L: $8 \mathrm{D}$ h photoperiod. Parasitized pupae were collected after 18 days.

\section{Juvenile development time}

Poinsettia plants, $25 \mathrm{~cm}$ heigh, were cut down to three leaves two days before infestation with whitefly. Small leaf clip cages ( $2 \mathrm{~cm}$ inside diameter), each containing 6 pairs of whitefly adults, were used to create three to four groups of third/fourth instar $B$. argentifolii on the underside of leaves. The adult whiteflies were introduced at 17:00 $\mathrm{h}$ and removed at 08:00 h the next day, as most eggs are laid between 6:00 am (lights on) to 8:00 am (van Lenteren \& Noldus, 1990). When the nymphs reached the third/fourth instar, female parasitoids were released in each group in a large clip cage (3.5 diameter), which covered the whole group of whitefly, which was larger than during the egg stage due to the movement of crawlers. About 5-6 parasitoids were released in each leaf cage and removed after $24 \mathrm{~h}$. Plants were kept in climate cabinets at $15,20,25$ or $32^{\circ} \mathrm{C}$. When parasitoids were on the verge of emerging from the pupae, daily counts were made of the number that had emerged.

The developmental times of the species/strains at different temperatures were compared using a one-way ANOVA test (SPSS for Windows, version 6). The effect of species or temperature was considered significant when $\mathrm{P}<0.05$ in a Least Significant Difference test.

\section{Lower developmental threshold for development}

We found that between $15^{\circ} \mathrm{C}$ and $25^{\circ} \mathrm{C}$ the relationship between temperature and development rate (the inverse of the development time) was linear with constant $\alpha$ and regression coefficient $\beta$ (see results). Using this linear relationship, the lower developmental threshold at which the development rate is zero $\left(T_{0}\right)$ was estimated as $-\alpha / \beta$, and the number of day degrees $\left({ }^{\circ} \mathrm{D}\right)$ as ${ }^{\circ} \mathrm{D}=$ development time $*\left(\mathrm{~T}-\mathrm{T}_{0}\right)$.

\section{Adult longevity}

Longevity of individual parasitoid females was measured in $36 \mathrm{ml}$ clear-plastic cups. The lids of the cups had a hole, $3 \mathrm{~cm}$ in diameter, which was covered with fine gauze to prevent a build up of moisture. Longevity without hosts was measured in cups containing only a few droplets of honey. Longevity with hosts was measured in cups containing a $0.5 \mathrm{~cm}$ layer of agar $(1 \%$ solution) on which a disc of a poinsettia leaf, underside up, infested with third or fourth instar $B$. argentifolii nymphs was placed. Each leaf disc was infested with about 100 nymphs. After two to three days, the females were transferred to a new cup with hosts. Cups were kept in climate cabinets at 15,20 or $25^{\circ} \mathrm{C}$. The number of females alive was checked daily. Longevity data were analysed using the Kaplan-Meier analysis (SPSS for Windows, Version 6), which allows the inclusion of the results from all the females used in the experiment, including those females that died an unnatural death because of handling, or escaped. In other methods only those females that die a natural death can be used to estimate longevity, which was usually a small fraction of the initial number of females used.

The longevities of species/strains at different temperatures were compared using one-way ANOVA test (SPSS for Win- dows, version 6). The effects of species and temperature were considered significant when $\mathrm{P}<0.05$ using a Least Significant Difference test. The effect of host availability on longevity was tested by using a two-sample t-test.

\section{Instar preference studies}

A poinsettia plant infested with $B$. argentifolii nymphs of all stages was cut down to three leaves and each leaf was enclosed in a leaf cage. Whole-leaf cages were made by taping the open ends of two clear-plastic $500 \mathrm{ml}$ cups together. Both bottoms were cut out, one of which was covered with fine screening, while the other was fitted with a clear-plastic lid that covered the leaf petiole. One parasitoid female was released per leaf cage (at $25^{\circ} \mathrm{C}$ and $60 \%$ R.H.). The number of whiteflies offered was in the range of 43-111, with an average of 66 per leaf. After $24 \mathrm{~h}$ the parasitoids were removed and the number of each instar present per leaf was counted and mapped to enable later identification of the instars that were parasitized. The plants were kept at $25^{\circ} \mathrm{C}$ and $60 \%$ R.H. for the duration of the development of the parasitoids.

In order to compare the distribution of parasitoid eggs over the different instars with the ratio of the instars on a leaf, a preference index was estimated for each female (see also Drost et al., 1999). This was necessary because 1) females were released onto leaves with slightly different ratios of whitefly instars, 2) it was unknown how many hosts of each instar were encountered per female, and 3) each female laid a different total number of eggs. If females are assumed to walk at a constant speed and the difference in size of the host nymphs is ignored, then the expected (expe) fraction of nymphs of instar $j$ parasitized by individual $i$ may be calculated by expressing the number of instar $j$ as a proportion of the total number of nymphs present:

$$
\text { expe }_{i, j}=\frac{\text { number of nymphs of instar } j}{\text { total number of nymphs }}
$$

The observed (obs) fraction of nymphs of instar $j$ parasitized by individual $i$ is

$$
\text { obs }_{\mathrm{i}, \mathrm{j}}=\frac{\text { number of parasitised nymphs of instar } j}{\text { total number of parasitised nymphs }}
$$

The deviation between the observed and expected values is a measure of the preference of individual $i$ for instar $j$ :

$$
\text { Preference }_{\mathrm{i}, \mathrm{j}}=\mathrm{obs}_{\mathrm{i}, \mathrm{j}}-\text { expe }_{\mathrm{i}, \mathrm{j}}
$$

The deviation will be zero when no preference occurs, positive when there is preference for a certain instar and negative when an instar is rejected. Thus, this method of analysis allows the detection of individual variation in instar preference. A onesample t-test was performed to test whether the preference is different from zero.

\section{Age-specific parasitism}

Parasitization of whitefly was achieved using the same procedure as in the development time experiment. One parasitoid female was introduced into a large clip cage enclosing a group of whitefly for exactly $24 \mathrm{~h}$ at either 15,20 or $25^{\circ} \mathrm{C}$ in a controlled climate cabinet. Two age groups of females were tested. In the first group females less than 24 hours old were used. In the second group three day old females of Encarsia strains and five day old females of Eretmocerus species were used. These females had been previously exposed to hosts over several days. After removal of the adult parasitoids, the plants were kept at $25^{\circ} \mathrm{C}$ until the parasitoids reached the pupal stage. When the parasitized nymphs changed colour from light to dark, they were counted in each infested group. In this way, the number of parasitized hosts was determined. 
TABLE 1. Juvenile development time (S.E. and number of replicates) of four aphelinid parasitoids, linear regression of development rate $\left(\right.$ at $\left.<30^{\circ} \mathrm{C}\right)$ against temperatures, estimated lower temperature thresholds $\left(\mathrm{T}_{0}\right)$ and day-degrees $\left({ }^{\circ} \mathrm{D}\right)$ for juvenile development. $\alpha$ and $\beta$ are constants, $r$ is coefficient of linear regression.

\begin{tabular}{|c|c|c|c|c|c|c|c|c|c|}
\hline \multirow{2}{*}{ Species } & \multicolumn{4}{|c|}{ Development time: mean (S.E.; n) } & \multirow{2}{*}{$\alpha$} & \multirow{2}{*}{$\beta$} & \multirow{2}{*}{$\mathrm{r}$} & \multirow{2}{*}{$\mathrm{T}_{0}$} & \multirow{2}{*}{${ }^{\circ} \mathrm{D}$} \\
\hline & $15^{\circ} \mathrm{C}$ & $20^{\circ} \mathrm{C}$ & $25^{\circ} \mathrm{C}$ & $32^{\circ} \mathrm{C}$ & & & & & \\
\hline E. formosa $\mathrm{D}^{1}$ & $62.8(0.46 ; 184) b^{2}$ & $29.8(0.26 ; 75) \mathrm{b}$ & $15.6(0.32 ; 24) \mathrm{a}$ & $13.6(0.45 ; 24) \mathrm{a}$ & -0.0505 & 0.004378 & 0.970 & $11.51 \mathrm{c}$ & $228 \mathrm{a}$ \\
\hline E. formosa $\mathrm{B}^{1}$ & $48.3(0.87 ; 40) \mathrm{a}$ & $28.0(0.48 ; 58) \mathrm{a}$ & $19.8(0.24 ; 126) \mathrm{d}$ & $14.8(0.13 ; 271) \mathrm{b}$ & -0.0247 & 0.003044 & 0.901 & $8.11 \mathrm{a}$ & $329 b$ \\
\hline E. eremicus & $79.3(1.36 ; 10) \mathrm{d}$ & $34.0(0.37 ; 88) \mathrm{c}$ & $18.6(0.57 ; 21) \mathrm{c}$ & $14.6(0.23 ; 71) \mathrm{b}$ & -0.0575 & 0.004409 & 0.928 & $13.04 \mathrm{~d}$ & $227 \mathrm{a}$ \\
\hline E. mundus & $64.0(0.29 ; 146) \mathrm{c}$ & $29.1(0.52 ; 39) \mathrm{ab}$ & $17.1(0.40 ; 43) \mathrm{b}$ & $13.7(0.19 ; 129) \mathrm{a}$ & -0.0499 & 0.004352 & 0.885 & $11.47 \mathrm{~b}$ & $230 \mathrm{a}$ \\
\hline
\end{tabular}

${ }^{1} E$. formosa $\mathrm{D}$ is the Dutch strain of E. formosa, E. formosa B the Beltsville strain.

${ }^{2}$ Different letters in a column indicate significant differences. One-way ANOVA with LSD $(P<0.05)$.

\section{Estimate of total parasitism}

Age-specific parasitism data were fitted to a function (1) that is composed of a linear function describing the increase of egg laying by a young adult parasitoid and an exponential function describing the decrease in egg laying by older adults (Enkegaard, 1993a). Temperature can be included in the model.

$$
\mathrm{F}_{x}=(\alpha+\beta \mathrm{T}) x \exp \{-(\delta+\varepsilon \mathrm{T}) x\}
$$

$\mathrm{F}_{\mathrm{x}}$ is the daily age-specific parasitism, $\mathrm{T}$ is the temperature, $x$ is the age of the parasitoids in days and $\alpha, \beta, \delta, \varepsilon$, are constants. The least square regression method was used with the Chisquare tolerant value of $10^{-6}$ using SPSS for Windows, version 6. The average life time parasitism $\mathrm{F}$ was estimated using the model:

$$
\mathrm{F}=\int_{0}^{y}(\alpha+\beta \mathrm{T}) \mathrm{y} \exp \{-(\delta+\varepsilon \mathrm{T}) \mathrm{y}\} \mathrm{dy}
$$

where $y$ is the average female longevity. The estimated total fecundity of different species/strains was compared using Chisquare tests.

\section{RESULTS}

\section{Juvenile development time}

The development time from egg to adult decreased exponentially from low to high temperatures (Table 1). At $15^{\circ} \mathrm{C}$ mean development time was shortest for $E$. formosa $\mathrm{B}$, longest for E. eremicus, and intermediate for $E$. formosa D and E. mundus. At $20^{\circ} \mathrm{C}$ E. eremicus had a longer mean development time than the other three parasitoids, whose development times did not differ significantly. At $25^{\circ} \mathrm{C}$ mean development time for E. formosa B was longer than that of E. eremicus, which was longer than that for E. mundus and E. formosa D. Differences in mean development time between species/strains decreased with increase in temperature. At $32^{\circ} \mathrm{C} \mathrm{E}$. formosa B and E. eremicus had identical mean development times, and that of E. formosa D was similar to that of $E$. mundus. The latter two species developed faster than the former two at $32^{\circ} \mathrm{C}$.

\section{Lower developmental threshold for development}

Linear regressions of the development rate against temperature were fitted for all species/strains. The $\alpha$ and $\beta$ values as well as the lower temperature threshold for $E$. formosa D and E. mundus were almost identical. E. formosa B had the lowest and E. eremicus the highest lower developmental threshold. Day-degrees necessary for the juvenile development of E. formosa D and the two Eretmocerus species were similar.

\section{Adult longevity}

Adult females of strains of Encarsia and of species of Eretmocerus lived longer at low temperatures in the presence or absence of hosts (Table 2), except for E. mundus for which the mean longevity at $25^{\circ} \mathrm{C}$ in the presence of hosts was slightly higher than that at $20^{\circ} \mathrm{C}$. At $25^{\circ} \mathrm{C}$, adult females of E. formosa D and Eretmocerus species lived longer in the absence of hosts. For E. formosa B there was no difference in the longevity of adults in the presence or absence of hosts. E. mundus lived longer in the presence of hosts than in their absence at $25^{\circ} \mathrm{C}$. $E$. mundus had the longest longevity of the four parasitoids at $15^{\circ} \mathrm{C}$ but the shortest at $25^{\circ} \mathrm{C}$ when hosts were absent. Longevity of E. mundus at $25^{\circ} \mathrm{C}$ was $89.5 \%$ shorter than that at $15^{\circ} \mathrm{C}$, which indicates a high sensitivity to temperature. E. formosa B was the least temperature sensitive, adult female longevity was $35 \%$ shorter at $25^{\circ} \mathrm{C}$ than at $15^{\circ} \mathrm{C}$. Adult females of this strain lived longest at $25^{\circ} \mathrm{C}$. When hosts were present, E. formosa B had the longest longevity at all three temperatures. Contrary to the results when hosts were absent, E. mundus showed

TABLE 2. Mean female adult longevity (days) of four aphelinid parasitoids of $B$. argentifolii in the absence and presence of $B$. argentifolii. S.E. and number of replicates are given between brackets.

\begin{tabular}{lccccccc}
\hline \multirow{2}{*}{ Species } & \multicolumn{3}{c}{ Hosts absent } & & \multicolumn{3}{c}{ Hosts present } \\
\cline { 2 - 3 } & \multicolumn{1}{c}{$15^{\circ} \mathrm{C}$} & $20^{\circ} \mathrm{C}$ & $25^{\circ} \mathrm{C}$ & & $15^{\circ}$ & $20^{\circ}$ & $25^{\circ}$ \\
\hline E. formosa $\mathrm{D}^{1}$ & $36.9(5.9 ; 15) \mathrm{a}^{2}$ & $22.5(3.4 ; 15) \mathrm{a}$ & $11.2(2.1 ; 15) \mathrm{ab}$ & & $23.0(1.2 ; 13) \mathrm{b}$ & $15.8(0.9 ; 12) \mathrm{a}$ & $7.8(0.9 ; 9) \mathrm{a}$ \\
E. formosa $\mathrm{B}^{1}$ & $47.2(3.8 ; 19) \mathrm{a}$ & $35.5(2.7 ; 20) \mathrm{b}$ & $30.5(2.5 ; 21) \mathrm{c}$ & & $50.4(4.5 ; 15) \mathrm{c}$ & $33.5(3.0 ; 13) \mathrm{b}$ & $28.6(2.7 ; 12) \mathrm{c}$ \\
E. eremicus & $38.4(3.6 ; 21) \mathrm{a}$ & $33.8(1.9 ; 22) \mathrm{b}$ & $18.9(1.6 ; 19) \mathrm{b}$ & & $24.3(1.3 ; 13) \mathrm{b}$ & $16.4(0.9 ; 12) \mathrm{a}$ & $9.3(0.4 ; 9) \mathrm{a}$ \\
E. mundus & $55.0(3.6 ; 14) \mathrm{b}$ & $24.5(2.7 ; 15) \mathrm{a}$ & $5.8(0.9 ; 15) \mathrm{a}$ & & $14.4(0.7 ; 15) \mathrm{a}$ & $11.3(1.3 ; 15) \mathrm{a}$ & $12.4(1.5 ; 11) \mathrm{b}$ \\
\hline
\end{tabular}

${ }^{1} E$. formosa D is the Dutch strain of E. formosa, E. formosa B the Beltsville strain.

${ }^{2}$ Different letters in a column indicate significant differences. One-way ANOVA with LSD $(P<0.05)$. 


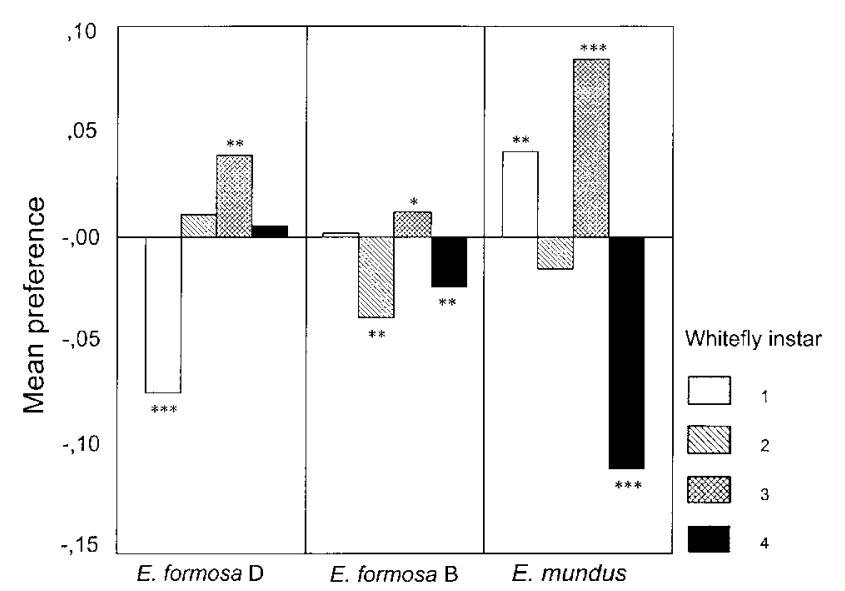

Fig. 1. Host instar preferences of three aphelinid parasitoids of $B$. argentifolii. Asterisks indicate a significant difference from zero based on t-test. *: $P<0.05 ;{ }^{* *} P<0.01$; ${ }^{* * *} P<$ 0.001 .

very little sensitivity to temperature when hosts were present: longevity only decreased by $13.9 \%$ at $25^{\circ} \mathrm{C}$ compared to that at $15^{\circ} \mathrm{C}$. Longevity does not seem to be genus or species specific. Large differences in longevity were found between the two Eretmocerus species and the Encarsia strains. Nevertheless the longevities of the adults of E. formosa D and E. eremicus, and their response to temperature and presence of hosts were analogous. These two species are normally reared on the same host, Trialeurodes vaporariorum.

\section{Instar preference}

The instar preferences of $E$. formosa D and B, and $E$. mundus were tested. All species/strains were offered all instars of $B$. argentifolii, but showed an obvious preference. $E$. formosa D preferred the third instar larvae of $B$. argentifolii $(t=2.77$, $\mathrm{df}=69, \mathrm{p}=0.007$ ) compared to other instars. Significantly fewer eggs were laid in $1^{\text {st }}$ instar nymphs than expected based on their abundance ( $t$ $=-4.36, \mathrm{df}=101, \mathrm{p}<0.0005)$ (Fig. 1). E. formosa $\mathrm{B}$ also preferred $3^{\text {rd }}$ instar nymphs for parasitism to the other nymphal stages $(t=3.69$, df $=113, \mathrm{p}=0.01)$. $E$. formosa $\mathrm{B}$ parasitized considerably fewer fourth instar nymphs ( $t$ $=-2.67, \mathrm{df}=113, \mathrm{p}=0.009)$ than expected. Third instar larvae were also the most preferred $(t=20.05$, df $=56$, $\mathrm{p}$ $<0.0005)$ and fourth instar nymphs the least preferred by E. mundus $(t=-25.2, \mathrm{df}=56, \mathrm{p}<0.0005)$. E. eremicus was not tested.

\section{Daily parasitism}

At $15^{\circ} \mathrm{C}$ daily parasitism by both age groups was low in all species/strains. In most cases daily parasitism was not significantly different from 0 (One sample T-test, p < 0.05 ) except for $E$. formosa D of both age groups and $E$. mundus of age group 0 (Table 3 ). Rates of parasitism were about the same at 20 and $25^{\circ} \mathrm{C}$ for all species/strains, and were higher than at $15^{\circ} \mathrm{C}$. On the first day, E. mundus had a much higher rate of parasitism at $20^{\circ} \mathrm{C}$ than the other parasitoid species/strains. It had a similar rate to E. eremicus, but higher than that of the two Encarsia strains at $25^{\circ} \mathrm{C}$. When three or five day old, the two Encarsia strains had a higher rate of parasitism at $20^{\circ} \mathrm{C}$ than the Eretmocerus species, while no differences were found between the four parasitoids at $25^{\circ} \mathrm{C}$. At 20 and $25^{\circ} \mathrm{C}$, the two Eretmocerus species had a higher rate of parasitism when 1 day old, whereas the two Encarsia strains had a higher rate of parasitism when 5 days old.

\section{Estimate of life-time parasitism}

The relationship between age-specific fecundity and adult age is described by model (1) for the four species/strains of parasitoids (Fig. 2). In general, the daily egg laying increased with increase in temperature. Daily reproduction increased with age up to a maximum, and thereafter decreased. Eretmocerus spp. oviposited at a higher rate when young than E. formosa. The latter maintained a high rate of reproduction for longer. The relationships of age-specific parasitism to adult age, based on the age-specific parasitism data from Table 3 are described in Table 4. There was no significant difference in the daily parasitism by the two Encarsia strains, but E. formosa B had a higher estimated total fecundity than E. formosa D at $20^{\circ} \mathrm{C}\left(\chi^{2}=7.30, \mathrm{df}=1, \mathrm{P}<0.01\right)$ (Table 3). E. mundus had a higher life-time parasitism than E. eremicus at 15 $\left(\chi^{2}=4.43\right.$, df $\left.=1, \mathrm{P}<0.05\right)$ and $20^{\circ} \mathrm{C}\left(\chi^{2}=9.57\right.$, $\mathrm{df}=1$, $\mathrm{P}<0.005)$. The two Eretmocerus spp. produced similar numbers of progeny at $25^{\circ} \mathrm{C}$.

\section{DISCUSSION}

\section{Juvenile development time}

Juvenile development times for the four aphelinid parasitoids of B. tabaci reported by other authors are listed in Table 5. In the present study, the juvenile development time of E. formosa D at 20 (29.8) and $25^{\circ} \mathrm{C}$ (15.6) corresponds to those reported by Enkegaard (1993b) (25.3 at $22^{\circ} \mathrm{C}$, and 14.0 at $28^{\circ} \mathrm{C}$ ), although Enkegaard found a

TABLE 3. Mean daily parasitism by $<1$ day old females and 3-day old females of Eretmocerus species and 5-day old females of Encarsia strains at different temperatures. S.E. and number of replicates are in brackets.

\begin{tabular}{lccccccc}
\hline \multirow{2}{*}{ Species } & \multicolumn{3}{c}{ Females of age $<1$} & & \multicolumn{3}{c}{ Females of age 3 or 5} \\
\cline { 2 - 3 } & \multicolumn{1}{c}{$15^{\circ} \mathrm{C}$} & $20^{\circ} \mathrm{C}$ & $25^{\circ} \mathrm{C}$ & & $15^{\circ}$ & $20^{\circ} \mathrm{C}$ & $25^{\circ} \mathrm{C}$ \\
\hline E. formosa $\mathrm{D}^{1}$ & $4.20(0.83 ; 15) \mathrm{b}^{2}$ & $8.87(0.70 ; 23) \mathrm{a}$ & $6.75(1.00 ; 8) \mathrm{a}$ & & $2.40(0.34 ; 10) \mathrm{b}$ & $11.22(1.28 ; 9) \mathrm{b}$ & $9.88(1.85 ; 8) \mathrm{a}$ \\
E. formosa $\mathrm{B}^{1}$ & $0.83(0.46 ; 12) \mathrm{a}$ & $7.04(0.68 ; 23) \mathrm{a}$ & $5.25(1.33 ; 8) \mathrm{a}$ & & $0.90(0.41 ; 10) \mathrm{ab}$ & $10.5(1.06 ; 6) \mathrm{b}$ & $10.38(0.89 ; 8) \mathrm{a}$ \\
E. eremicus & $1.50(0.85 ; 12) \mathrm{a}$ & $6.69(1.01 ; 26) \mathrm{a}$ & $16.00(4.57 ; 8) \mathrm{ab}$ & & $0.63(0.25 ; 38) \mathrm{a}$ & $0.71(0.71 ; 7) \mathrm{a}$ & $3.91(1.60 ; 11) \mathrm{a}$ \\
E. mundus & $2.26(0.86 ; 19) \mathrm{ab}$ & $16.33(1.28 ; 12) \mathrm{b}$ & $19.81(2.15 ; 16) \mathrm{b}$ & & $0.56(0.41 ; 18) \mathrm{a}$ & $3.58(1.18 ; 12) \mathrm{a}$ & $4.00(2.04 ; 7) \mathrm{a}$ \\
\hline
\end{tabular}

${ }^{1} E$. formosa D is the Dutch strain of E. formosa, E. formosa B the Beltsville strain.

${ }^{2}$ Different letters in a column indicate significant differences. One-way ANOVA with LSD $(P<0.05)$. 


\section{E. formosa D}

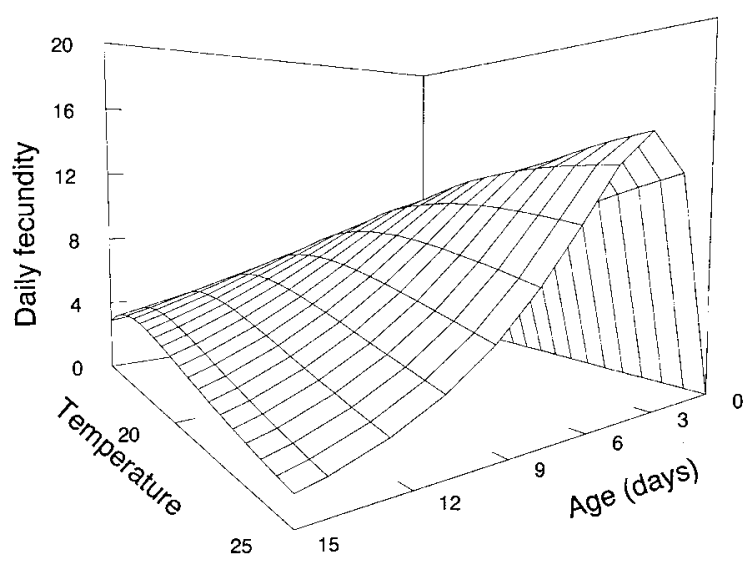

E. eremicus

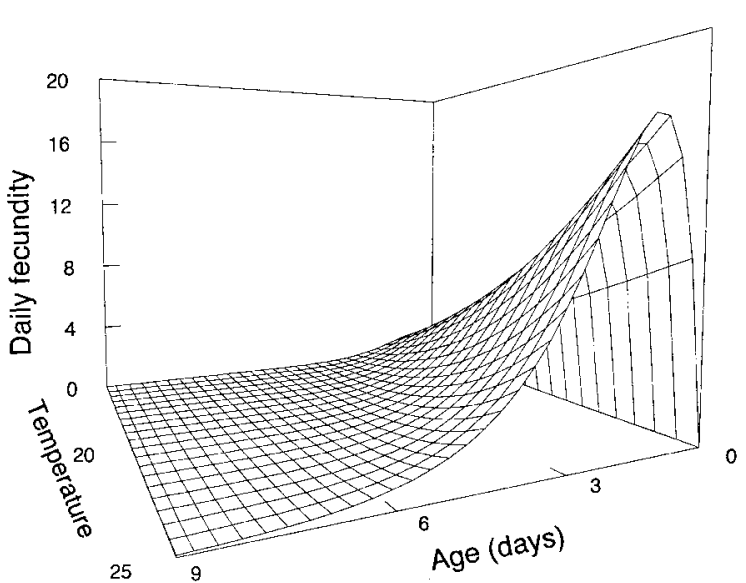

E. formosa B

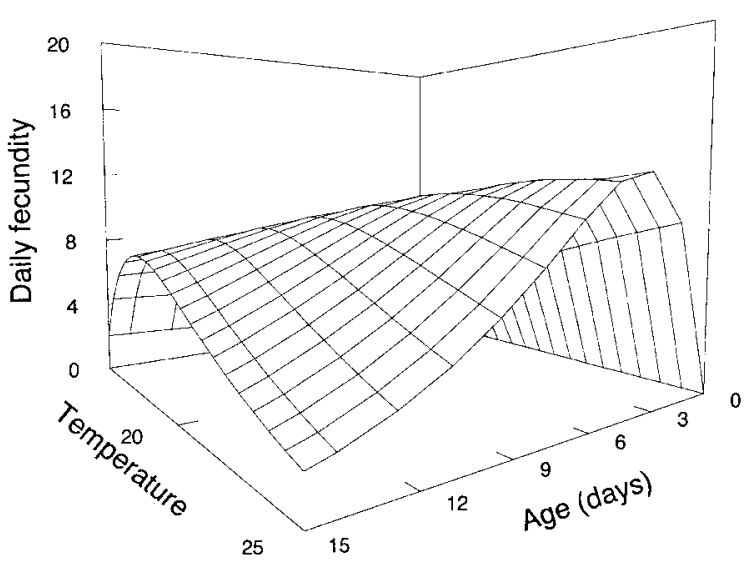

E. mundus

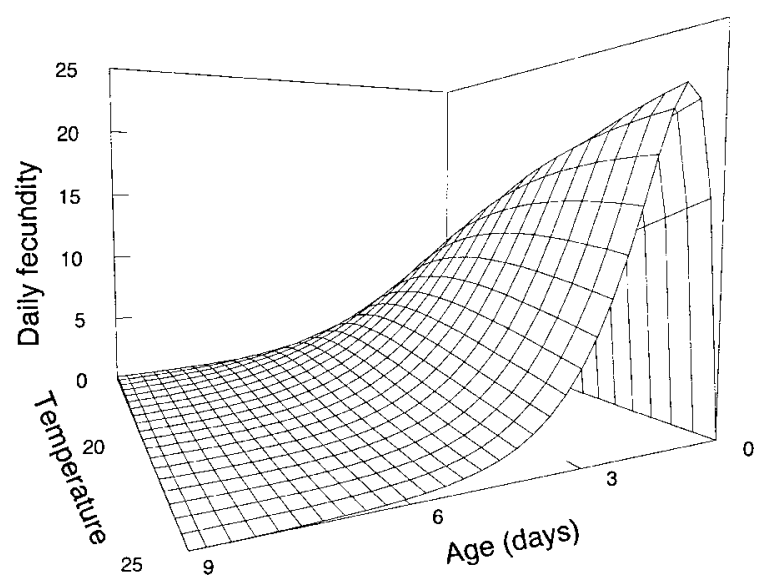

Fig. 2. Fitted curves for age-specific fecundity over a range of temperatures for four aphelinid parasitoids of B. argentifolii.

longer development time at $16^{\circ} \mathrm{C}(72.8)$ than we did at $15^{\circ} \mathrm{C}$ (62.8). Because of the longer development time the T0 (13.3) value cited by Enkegaard is also higher than we found (11.5). Consequently the day-degrees value (207) is lower than recorded here (228). The host plant cultivar we used (Goldfinger) is different from that by Enkegaard (Angelica), which might be the reason for the different results. Notable differences between the two Encarsia strains were observed in our study. The linear regressions of development rate against temperature ( $\alpha$ and $\beta$ values are different from each other) and the $\mathrm{T}_{0}$ and ${ }^{\circ} \mathrm{D}$ values were different for the two strains. At temperatures below $20^{\circ} \mathrm{C}, \mathrm{E}$. formosa $\mathrm{B}$ had a higher development rate than E. formosa D. E. formosa B had a lower $\mathrm{T}_{0}$ value (8.1) than the other parasitoids (11.5, 13.4 and 11.5). The $\mathrm{T}_{0}$ value was also lower than that of the host, $B$. argentifolii (13.9) (Enkegaard, 1993a). The two Eretmocerus species and E. formosa D required fewer day-degrees for development than B. tabaci (B type) on poinsettia $\left(327^{\circ} \mathrm{C}\right.$ ) (Enkegaard, 1993a); E. formosa B and B. tabaci had similar values (Enkegaard, 1993a). These values might indicate that $E$. formosa B has a better capacity to control

TABLE 4. Estimated coefficients: $\alpha, \beta, \delta$ and $\varepsilon$, coefficient of determination $r^{2}$ of the age-specific function (1), and estimated lifetime parasitism $\left(\mathrm{F}_{\text {est }}\right)$ at different temperatures of four aphelinid parasitoids of B. argentifolii.

\begin{tabular}{|c|c|c|c|c|c|c|c|c|c|c|c|c|}
\hline Species & \multicolumn{3}{|c|}{ E. formosa $\mathrm{D}^{*}$} & \multicolumn{3}{|c|}{ E. formosa $\mathrm{B}^{*}$} & \multicolumn{3}{|c|}{ E. eremicus } & \multicolumn{3}{|c|}{ E. mundus } \\
\hline$\alpha$ & \multicolumn{3}{|c|}{-15.281} & \multicolumn{3}{|c|}{-13.215} & \multicolumn{3}{|c|}{-42.711} & \multicolumn{3}{|c|}{-94.701} \\
\hline$\beta$ & \multicolumn{3}{|c|}{1.125} & \multicolumn{3}{|c|}{0.900} & \multicolumn{3}{|c|}{3.326} & \multicolumn{3}{|c|}{6.553} \\
\hline$\delta$ & \multicolumn{3}{|c|}{-0.155} & \multicolumn{3}{|c|}{-0.300} & \multicolumn{3}{|c|}{2.57} & \multicolumn{3}{|c|}{-0.374} \\
\hline$\varepsilon$ & \multicolumn{3}{|c|}{0.029} & \multicolumn{3}{|c|}{0.023} & \multicolumn{3}{|c|}{-0.066} & \multicolumn{3}{|c|}{0.063} \\
\hline$r^{2}$ & \multicolumn{3}{|c|}{0.710} & \multicolumn{3}{|c|}{0.887} & \multicolumn{3}{|c|}{0.998} & \multicolumn{3}{|c|}{0.976} \\
\hline Temperature & 15 & 20 & 25 & 15 & 20 & 25 & 15 & 20 & 25 & 15 & 20 & 25 \\
\hline $\mathrm{F}_{\text {est }}$ & 62.5 & 94.5 & 80.9 & 75.8 & 156.6 & 109.6 & 2.3 & 13.2 & 43.6 & 10.7 & 43.4 & 42.5 \\
\hline
\end{tabular}

* E. formosa D is the Dutch strain of E. formosa, E. formosa B the Beltsville strain. 
TABLE 5. Development times of four aphelinid parasitoids on B. tabaci reported by various authors (Only results from laboratory experiments at constant temperatures are included).

\begin{tabular}{lcccccc}
\hline Species & Origin & Test plant & Temp. $\left({ }^{\circ} \mathrm{C}\right)$ & $\begin{array}{c}\text { Development } \\
\text { time }\end{array}$ & $\mathrm{n}$ & Reference \\
\hline Encarsia formosa & Holland & Poinsettia/ Angelica & 16 & $72.80 \pm 0.90$ & 115 & Enkegaard, 1993b \\
Encarsia formosa & Holland & Poinsettia/ Angelica & 22 & $25.30 \pm 0.30$ & 100 & Enkegaard, 1993b \\
Encarsia formosa & Holland & Poinsettia/ Angelica & 28 & $14.00 \pm 0.20$ & 121 & Enkegaard, 1993b \\
Eretmocerus eremicus & Oxnard, CA & Sweet potato & 15 & $63.3 \pm 0.13$ & 33 & Greenberg et al., 2000 \\
Eretmocerus eremicus & Oxnard, CA & Sweet potato & 21 & $26.4 \pm 0.16$ & 69 & Greenberg et al., 2000 \\
Eretmocerus eremicus & Oxnard, CA & Sweet potato & 24 & $21.1 \pm 0.16$ & 211 & Greenberg et al., 2000 \\
Eretmocerus eremicus & Oxnard, CA & Sweet potato & 32 & $18.1 \pm 0.16$ & 169 & Greenberg et al., 2000 \\
Eretmocerus eremicus & Hawaii & cotton & 20 & $33.95 \pm 0.31$ & 97 & Powell \& Bellows, 1992 \\
Eretmocerus eremicus & Hawaii & cotton & 29 & $18.76 \pm 0.15$ & 158 & Powell \& Bellows, 1992 \\
Eretmocerus eremicus & Hawaii & cucumber & 20 & $35.06 \pm 0.14$ & 345 & Powell \& Bellows, 1992 \\
Eretmocerus eremicus & Hawaii & cucumber & 29 & $16.10 \pm 0.11$ & 185 & Powell \& Bellows, 1992 \\
Eretmocerus eremicus & Indio. CA & cotton & 20 & $35.78 \pm 0.46$ & 60 & Powell \& Bellows, 1992 \\
Eretmocerus eremicus & Indio. CA & cotton & 29 & $18.31 \pm 0.46$ & 32 & Powell \& Bellows, 1992 \\
Eretmocerus eremicus & Indio. CA & cucumber & 20 & $36.39 \pm 0.22$ & 196 & Powell \& Bellows, 1992 \\
Eretmocerus eremicus & Indio. CA & cucumber & 29 & $16.29 \pm 0.13$ & 196 & Powell \& Bellows, 1992 \\
Eretmocerus mundus & Israel & cotton & 29.5 & 30.00 & & Gameel, 1969 \\
Eretmocerus mundus & Spain & sweet potato & 26 & 15.4 & Jones \& Greenberg, 1998 \\
Eretmocerus mundus & Jordan & tomato & 14 & 44.00 & Sharaf \& Batta, 1985 \\
Eretmocerus mundus & Jordan & tomato & 25 & 16.00 & Sharaf \& Batta, 1985 \\
Eretmocerus mundus & Egypt & sweet potato & 29.8 & 17.90 & 35 & Tawfik et al., 1978 \\
\hline
\end{tabular}

whiteflies at low temperatures. E. formosa D and $E$. mundus have more or less identical $\alpha, \beta, \mathrm{T}_{0}$ and ${ }^{\circ} \mathrm{D}$ values. Developmental times of E. eremicus on B. argentifolii recorded by Greenberg et al. (2000) were less sensitive to temperature change than we observed. The differences might be due to the different host plants used and/or the fact that the parasitoid strain used in their experiments were reared on the same host as was used in the experiments. In another study, Greenberg et al. (2002) found that E. mundus developed faster on Bemisia than on Trialeurodes, which is similar to what we found. Powell \& Bellows (1992) tested the effect of the host plant on the development time of two strains of $E$. eremicus on B. tabaci at 20 and $29^{\circ} \mathrm{C}$. The development time on cotton at $20^{\circ} \mathrm{C}$ (33.9 days) is similar to our result (34.0 days) in spite of different host plants. Similarly, the development time for $E$. mundus measured at $25^{\circ} \mathrm{C}$ corresponds with the result of Sharaf \& Beatta (1985) (16 days) at the same temperature, and also was in the same range as the results of Jones \& Greenberg (1998) at $26^{\circ} \mathrm{C}$. Sharaf \& Batta (1985) found a much shorter development time at $14^{\circ} \mathrm{C}$ (44 days) than we found at $15^{\circ} \mathrm{C}$ (64 days).

\section{Adult longevity}

Vet \& van Lenteren (1981) and van Lenteren et al. (1987) compared the longevity of E. formosa at different temperatures in the presence or absence of hosts reported by different authors, and concluded that being given access to hosts shortened adult longevity in E. formosa, but not in Eretmocerus species. In the present study adult longevity was shorter in the presence than absence of hosts in E. formosa D and the two Eremocerus species.
Adult female longevity is shorter in the presence of hosts in another parasitoid of Bemisia, Amitus bennetti Viggiani \& Evans (Hymenoptera: Platygasteridae) (Drost et al., 1999). Shorter adult life-spans in the presence of hosts is found in other parasitoids. Takagi (1985) recorded the highest longevity in female Pteromalus puparum (Hymenoptera: Pteromalidae), a gregarious parasitoid of many butterfly pupae, when they are kept with honey but without hosts. Nakamura (1994) reported a negative correlation between adult female longevity in Exorista japonica (Diptera: Tachinidae) and frequency of oviposition, when the common armyworm Pseudaletia separata (Lepidoptera: Noctuidae) is used as a host. The shorter life span recorded here might be caused by transferring the parasitoids to fresh hosts every two or three days. However, life-span did not differ in E. formosa B in the presence or absence of hosts, and this parasitoid lived longer than Eretmocerus species and E. formosa D in both situations. It is important to realize that the two strains of $E$. formosa are normally reared on different hosts: E. formosa B on B. argentifolii and E. formosa D on T. vaporariorum. Bethke et al. (1991) report a longer adult longevity for E. formosa reared on B. tabaci $(8.3$ days) than when reared on $T$. vaporariorum (4.8 days) when $B$. tabaci nymphs were present.

Longevities of $E$. formosa reared on $T$. vaporariorum and tested in the presence of $B$. tabaci or T. vaporariorum were very different. Van Lenteren et al. (1987) studied the effect of host quality on adult longevity of $E$. formosa, and discovered a longer longevity when all instars of $T$. vaporariorum larvae were present during the test, than 
TABLE 6. Adult longevities of four aphelinid parasitoids of B. argentifolii reported by various authors (Only results from laboratory experiments at constant temperatures are included).

\begin{tabular}{lccccccc}
\hline Species & Origin & Temp. $\left({ }^{\circ} \mathrm{C}\right)$ & Longevity & $\mathrm{n}$ & Hosts & Honey & Reference \\
\hline Encarsia formosa & Holland & 16 & $30.1 \pm 2.5$ & 23 & yes & no & Enkegaard, 1993b \\
Encarsia formosa & Holland & 22 & $15.2 \pm 0.9$ & 22 & yes & no & Enkegaard, 1993b \\
Encarsia formosa & Holland & 28 & $9.2 \pm 0.8$ & 28 & yes & no & Enkegaard, 1993b \\
Encarsia formosa & Beltsville & 27.6 & $7.7 \pm 0.4$ & 30 & yes & no & Heinz \& Parrella, 1994 \\
Encarsia formosa & Canada & 27.6 & $3.9 \pm 0.2$ & 29 & yes & no & Heinz \& Parrella, 1994 \\
Eretmocerus eremicus & CA & 28 & $5.0 \pm 0.5$ & 36 & yes & no & Headrick et al., 1999 \\
Eretmocerus eremicus & CA & 1.7 & $8.4 \pm 0.1$ & 46 & no & yes & Gerling, 1966 \\
Eretmocerus eremicus & CA & 15.5 & $40.5 \pm 7.9$ & 7 & no & yes & Gerling, 1966 \\
Eretmocerus eremicus & CA & 26.7 & $8.6 \pm 0.2$ & 15 & no & yes & Gerling, 1966 \\
Eretmocerus mundus & Egypt & 18 & 7.6 & 25 & yes & yes & Tawfik et al., 1978 \\
Eretmocerus mundus & Egypt & 30 & 10.5 & 25 & yes & yes & Tawfik et al., 1978 \\
Eretmocerus mundus & Jordan & 14 & 11.3 & 18 & yes & no & Sharaf \& Batta, 1985 \\
Eretmocerus mundus & Jordan & 25 & 9.1 & 17 & yes & no & Sharaf \& Batta, 1985 \\
Eretmocerus mundus & Jordan & 14 & 14.8 & & yes & no & Sharaf \& Batta, 1985 \\
Eretmocerus mundus & Jordan & 25 & 9.6 & & yes & no & Sharaf \& Batta, 1985 \\
Eretmocerus mundus & Egypt & 23 & 3.22 & 34 & no & no & Tawfik et al., 1978 \\
Eretmocerus mundus & Egypt & 18 & 4.2 & 15 & no & no & Tawfik et al., 1978 \\
Eretmocerus mundus & Egypt & 18 & 5.3 & 20 & no & yes & Tawfik et al., 1978 \\
Eretmocerus mundus & Egypt & 10 & 6.1 & 20 & no & yes & Tawfik et al., 1978 \\
Eretmocerus mundus & Egypt & -4 & 0.42 & 10 & no & no & Tawfik et al., 1978 \\
Eretmocerus mundus & Israel & 25 & 7.65 & & no & yes & El-Ghany et al., 1990 \\
\hline
\end{tabular}

when only $1^{\text {st }}$ instar larvae were present, which are not suitable for parasitism. It seems that the presence of "poor" quality hosts shortens the life-span of adult E. formosa although further investigation is needed. Our results showed that in the absence of hosts adult E. formosa B lived longer than E. formosa $\mathrm{D}$ in spite of the fact that the latter was reared on a more favourable host. This indicates an intrinsic or even heritable difference between the strains. Heritable differences have been found between these two strains in their host acceptance, host handling behaviour, immature development, immature survival and rate of parasitism (van Lenteren et al., 1997; Henter \& van Lenteren, 1996; Henter et al., 1996). A large difference in the life-spans of the two E. formosa strains was found when hosts were present. This might be the result of the type of host present during the experiment. For $E$. formosa D, B. argentifolii was a strange host, whereas $E$. formosa $\mathrm{B}$ might have adapted to $B$. argentifolii after generations of cultivation on this host. Heinz \& Parrella (1994, Table 6) record a longer longevity in E. formosa B (7.7 days) than in a Canadian commercial strain of E. formosa (3.9 days) at $27^{\circ} \mathrm{C}$ when reared on B. argentifolii. The Canadian commercial strain is supposedly $E$. formosa D.

We recorded a comparatively longer longevity for both E. formosa $\mathrm{B}$ and E. formosa $\mathrm{D}$ at $25^{\circ} \mathrm{C}$. Enkegaard (1993b) records a longer longevity for $E$. formosa when hosts were present than we found for $E$. formosa $\mathrm{D}$ when hosts were present (Table 6). The difference might be due to different methods of offering the hosts. Longevity of $E$. eremicus at $15^{\circ} \mathrm{C}$ without hosts (38.4) is in the same range as Gerling's results (1966) at $15.5^{\circ} \mathrm{C}(40.5) . E$. mundus had a longer longevity at $20^{\circ} \mathrm{C}$ (33.8) than Tawfik et al. (1978) records at $18^{\circ} \mathrm{C}(5.3)$, and a slightly shorter longevity at $25^{\circ} \mathrm{C}$ (5.8) than El-Ghany et al. (1990) records (7.65) when hosts are absent. When hosts were present we recorded a longer life-span (12.4) for $E$. mundus at $25^{\circ} \mathrm{C}$ than Sharaf \& Batta found (9.6) (1985).

\section{Instar preference}

The results on host-stage preference indicate that both Encarsia strains showed a preference for $3^{\text {rd }}$ instar Bemisia nymphs. This does not agree with Enkegaard's (1993b) results, which indicate that $4^{\text {th }}$ instar Bemisia nymphs are preferred. Enkegaard observed the oviposition behaviour for $1 / 2$ to $21 / 2$ hours, while in our experiment parasitoids were left to parasitize for 24 hours. This difference might account for the different results. Jones and Greenberg (1998) record that E. mundus laid most eggs under $2^{\text {nd }}$ instar nymphs of $B$. argentifolii in a nochoice test. In E. mundus the strongest preference for $3^{\text {rd }}$ instar nymphs was observed when all host stages were available. This result agrees with that of Foltyn \& Gerling (1985) who also used a mixed-age host population. McAuslane \& Nguyen (1996) report that the third instar nymphal stage of $B$. argentifolii is the most favourable host stage for an Eretmocerus spp.

\section{Daily and life-time parasitism}

Encarsia and Eremocerus species are synovigenic, which means that females mature eggs during their adult life. Encarsia species are anautogenous, which means that females do not have mature eggs in their ovaries at emer- 
TABLE 7. Fecundities of four aphelinid parasitoids of $B$. argentifolii reported by various authors. (Only results from laboratory experiments at constant temperatures are included).

\begin{tabular}{|c|c|c|c|c|c|c|c|c|}
\hline Species & Origin & $\begin{array}{l}\text { Rear. } \\
\text { host }\end{array}$ & Test plant/ cultivar & Temp. $\left({ }^{\circ} \mathrm{C}\right)$ & Fecundity & S.E. & $\mathrm{n}$ & References \\
\hline E. formosa & England & T.v. & Poinsettia/ A.H.B.D. & 26.7 & 26.7 & & & Bethke, et al., 1991 \\
\hline E. formosa & CA, USA & B.t. & Poinsettia/ A.H.B.D. & 26.7 & 30.2 & & & Bethke, et al., 1991 \\
\hline E. formosa & Holland & & Poinsettia/ Angelica & 16 & $0.8 / \mathrm{d}$ & & & Enkegaard, 1994 \\
\hline E. formosa & Holland & & Poinsettia/ Angelica & 22 & $5.6 / \mathrm{d}$ & & & Enkegaard, 1994 \\
\hline E. formosa & Holland & & Poinsettia/ Angelica & 28 & $10.4 / \mathrm{d}$ & & & Enkegaard, 1994 \\
\hline E. formosa & Canada & T.v. & Poinsettia/ Lilo & 27.6 & $2.0 / 3 \mathrm{~d}$ & 0.3 & 30 & Heinz \& Parrella, 1994 \\
\hline E. formosa & Canada & T.v. & Poinsettia/ A.H.B.D. & 27.6 & $1.9 / 3 \mathrm{~d}$ & 0.3 & 30 & Heinz \& Parrella, 1994 \\
\hline E. formosa & Beltsville & B.t. & Poinsettia/ Lilo & 27.6 & $8.0 / 3 \mathrm{~d}$ & 0.6 & 30 & Heinz \& Parrella, 1994 \\
\hline E. formosa & Beltsville & B.t. & Poinsettia/ A.H.B.D. & 27.6 & $6.7 / 3 \mathrm{~d}$ & 0.6 & 30 & Heinz \& Parrella, 1994 \\
\hline E. formosa & Holland & T.v. & Poinsettia & 22.5 & 59.2 & & & Szabo et al., 1993 \\
\hline E. formosa & Holland & B.t. & Poinsettia & 22.5 & 51.3 & & & Szabo et al., 1993 \\
\hline E. eremicus & CA, USA & B.a. & cotton & 28 & 23.1 & 5.6 & & Headrick et al., 1999 \\
\hline E. eremicus & Hawaii & B.t. & cotton & 20 & 23.5 & 13.7 & 6 & Powell \& Bellows, 1992 \\
\hline E. eremicus & Hawaii & B.t. & cotton & 29 & 41.1 & 48 & 7 & Powell \& Bellows, 1992 \\
\hline E. eremicus & Hawaii & B.t. & cucumber & 20 & 43 & 23.8 & 10 & Powell \& Bellows, 1992 \\
\hline E. eremicus & Hawaii & B.t. & cucumber & 29 & 47 & 37.1 & 5 & Powell \& Bellows, 1992 \\
\hline E. eremicus & Indio. CA & B.t. & cotton & 20 & 31.4 & 25.8 & 7 & Powell \& Bellows, 1992 \\
\hline E. eremicus & Indio. CA & B.t. & cotton & 29 & 20 & 15.1 & 5 & Powell \& Bellows, 1992 \\
\hline E. eremicus & Indio. CA & B.t. & cucumber & 20 & 27.8 & 15.2 & 10 & Powell \& Bellows, 1992 \\
\hline E. eremicus & Indio. CA & B.t. & cucumber & 29 & 35.9 & 18.1 & 11 & Powell \& Bellows, 1992 \\
\hline E. mundus & Jodan & B.t. & tomato & 14 & 20 & & 8 & Sharaf \& Batta, 1985 \\
\hline E. mundus & Jodan & B.t. & tomato & 25 & 27.4 & & 8 & Sharaf \& Batta, 1985 \\
\hline E. mundus & Egypt & B.t. & sweet potato & 18 & 14.5 & & 25 & Tawfik et al., 1978 \\
\hline E. mundus & Egypt & B.a. & sweet potato & 30 & 48 & & 25 & Tawfik et al., 1978 \\
\hline
\end{tabular}

gence. Eremocerus species are autogenous as the adults already have a number of mature eggs in their ovaries at emergence (Headrick et al., 1999). This difference in egg maturation leads to different patterns in age-specific fecundity. Encarsia species have a low rate of parasitism at emergence, which increases gradually to a maximum level, which is maintained for some time and then decreases to zero during the last phase of adult life. Egg laying in Encarsia occurs during most of adult life. In Eretmocerus species, however, the maximum rate of parasitism occurs shortly after emergence and then quickly decreases. Here, most eggs were deposited by young females. The daily rates of parasitism recorded for E. formosa $\mathrm{D}$ at $25^{\circ} \mathrm{C}$ are similar to those found at $28^{\circ} \mathrm{C}$ by Enkegaard (1994), but were higher at 15 and $20^{\circ} \mathrm{C}$ than found by Enkegaard (Table 7). Bethke et al. (1991) found a higher fecundity for an E. formosa strain reared for 18 generations on $B$. tabaci than a strain reared on $T$. vaporariorum (Table 7), which suggests adaptation to the rearing host. E. formosa B had a higher fecundity than $E$. formosa $\mathrm{D}$ at $20^{\circ} \mathrm{C}$ according to our estimate, which might also be due to host adaptation. Heinz \& Parrella (1994) record a higher rate of parasitism for E. formosa B than a Canadian E. formosa strain, although the rates were quite low for both strains. The estimated fecundity for E. eremicus at $20^{\circ} \mathrm{C}$ obtained in this study was slightly lower than Powell \& Bellows (1992) record.
Sharaf \& Batta (1985) record a slightly higher fecundity for $E$. mundus at $14^{\circ} \mathrm{C}$ than we estimated at $15^{\circ} \mathrm{C}$, and a slightly lower fecundity (27.4) than we estimated (42.5) at $25^{\circ} \mathrm{C}$.

\section{Epilogue}

Our results show that E. formosa B has the shortest development time, the longest life-span in the presence of hosts, and the highest fecundity at temperatures lower than $20^{\circ} \mathrm{C}$, which indicates that this parasitoid is a favourable candidate for Bemisia control at low temperatures. At temperatures higher than $20^{\circ} \mathrm{C}$, the Eretmocerus species perform better. In Europe, biological control of $B$. tabaci in greenhouses is currently achieved by releasing two species of parasitoids: either E. formosa and E. eremicus (both parasitoids attack Bemisia and Trialeurodes) or E. formosa and E. mundus (Encarsia attacks both species of whitefly, E. mundus only attacks Bemisia) (Gerling et al., 2001). The mixture of E. formosa and $E$. eremicus has successfully been applied on a large scale for several years, e.g. on 500 ha of tomato and 1000 ha of pepper in Spain (Gerling et al., 2001). The use of two species is based on: (1) The Eretmocerus species are excellent parasitoids of $B$. argentifolii, and (2) they are effective at relatively high temperatures; (3) E. formosa is an excellent parasitoid of $T$. vaporariorum, which often occurs together with $B$. argentifolii in Mediterranean 
Europe, and (4) this species is effective at relatively low temperatures.

There might, however, be another good reason for using a mix of parasitoid species. Eretmocerus species and Amitus species even more so, mainly parasitize hosts during the first days of their adult life (Eretmocerus eremicus up to 62/day, Soler, 2003; Amitus bennetti up to 99/day, Drost et al., 1999). Encarsia species produce few eggs per day (up to 12/day, Vet et al., 1981). The fast reproducing species like Amitus and Eretmocerus might be best suited for reducing high density whitefly populations, while the Encarsia species can be used to maintain whitefly population at low densities.

That a mix of parasitoid species with very different life histories might be very effective for whitefly control is true not only for greenhouses in the Mediterranean, but also for classical biological control, where, for example, proovigenic Amitus species were combined with synovigenic Encarsia species. Aleurocanthus woglumi, the citrus blackfly was successfully controlled in Mexico and the USA by introducing 4 species of parasitoids: at the start of the introductions and when host density was very high, the pro-ovigenic Amitus hesperidum was the dominant parasitoid, and aphelinids like Encarsia opulenta were rarely found. When host densities become low as a result of parasitism by $A$. hesperidum, E. opulenta become the dominant parasitoid (Flanders, 1969; Thompson et al, 1987; Dowell et al, 1981; Nguyen \& Hamon, 1994).

ACKNOWLEDGEMENTS. F. van den Bosch is thanked for his advice on how to estimate life-time fecundity. J.A. Harvey and A. Enkegaard are acknowledged for critically reviewing the manuscript. The research was supported by the Technology Foundation (STW), which is subsidized by the Netherlands Organisation for Scientific Research (NWO).

\section{REFERENCES}

Bellows T.S.Jr., Perring T.M., Gill R.J.,\& Headrick D.H 1994: Description of a new species of Bemisia (Homoptera: Aleyrodidae). Ann. Entomol. Soc. Am. 87: 195-206.

Bentz J.A., Reeves J. III, Barbosa P. \& Francis B. 1996: The effect of nitrogen fertilizer applied to Euphorbia pulcherrima on the parasitization of Bemisia argentifolii by the parasitoid Encarsia formosa. Entomol. Exp. Appl. 78: 105-110.

Bethke J.A., Nuessly G.S., Paine T.D. \& Redak R.A. 1991: Effect of host insect-host plant associations on selected fitness components of Encarsia formosa (Gahan) (Hymenoptera: Aphelinidae). Biol. Control 1: 164-169.

Brown J.K., Frohlich D.R. \& Rosell R.C. 1995: The sweetpotato or silverleaf whiteflies: biotypes of Bemisia tabaci of a species complex? Annu. Rev. Entomol. 40: 511-534.

Cahill M., Gorman K., Day S. \& Denholm I. 1996: Baseline determination and detection of resistance to imidacloprid in Bemisia tabaci (Homoptera: Aleyrodidae). Bull. Entomol. Res. 86: 343-349.

Costa H.S., Brown J.K., Sivasupramaniam S. \& Bird J. 1993: Regional distribution, insecticide resistance, and reciprocal crosses between the A and B biotypes of B. tabaci. Ins. Scien. Appl. 14: 255-266.

DeBarro P.J., Hart P.J. \& Morton R. 2000: The biology of two Eretmocerus spp. (Haldeman) and three Encarsia spp. Forster and their potential as biological agents of Bemisia tabaci biotype $\mathrm{B}$ in Australia. Entomol. Exp. Appl. 94: 93-102.

de Vis R.M.J., Mendez H., van Lenteren J.C. 2003: Comparison of foraging behavior, interspecific host discrimination, and competition of Encarsia formosa and Amitus fuscipennis. $J$. Ins. Behav. 16: 117-152.

Dowell R.V., Cherry R.H., Fitzpatrick G.E., Reinert J.A. \& KNAPP J.L. 1981: Biology, plant-insect relations and control of the citrus blackfly. Institute of Food and Agricultural Sciences. University of Florida, Gainesville. Florida Agric. Exp. Stat. Tech. Bull. 818: 49.

Drost Y.C., van Lenteren J.C. \& van Roermund H.J.W. 1998: Life-history parameters of different biotypes of Bemisia tabaci (Hemiptera: Aleyrodidae) in relation to temperature and host plant: a selective review. Bull. Entomol. Res. 88: 219-229.

Drost Y.C., Qiu Y.T., Posthuma-Doodeman C.J.A.M. \& van LENTEREN J.C. 1999: Life-history and oviposition behaviour of Amitus bennetti, a parasitoid of Bemisia argentifolii. Entomol. Exp. Appl. 90: 183-189.

Drost Y.C., Qiu Y.T., Posthuma-Doodeman C.J.A.M. \& van LENTEREN J.C. 2000: Comparison of searching strategies of five parasitoid species of Bemisia argentifolii. J. Appl. Entomol. 124: 105-112.

El-Ghany A., El-Sayed M., Afifi F.M.L., Haydar M.F. 1990: Inter-effects of temperature and type of food on adult longevity of Eretmocerus mundus Merect, a primary parasitoid of Bemisia tabaci (Genn.). Bull. Fac. Agr., Univ. Cairo 41: 913-922

ENKEGAARD A. 1993a: The poinsettia strain of the cotton whitefly, Bemisia tabaci (Homoptera: Aleyrodidae), biological and demographic parameteters on poinsettia (Euphorbia pulcherrima) in relation to temperature. Bull. Entomol. Res. 83: 535-546.

ENKEGAARD A. 1993b: Encarsia formosa parasitizing the Poinsettia-strain of the cotton whitefly, Bemisia tabaci, on Poinsettia: bionomics in relation to temperature. Entomol. Exp. Appl. 69: 251-261.

EnKEgaARD A. 1994: Temperature dependent functional response of Encarsia formosa parasitizing the Poinsettia-strain of the cotton whitefly Bemisia tabaci on Poinsettia. Entomol. Exp. Appl. 73: 19-29.

Faria F. \& Wraight S.P. 2001: Biological control of Bemisia tabaci with fungi. Crop Prot. 20: 767-778.

FLANDERS S.E. 1969: Herbert D. Smith's observations on citrus blackfly parasites in India and Mexico and the correlated circumstances. Can. Entomol. 101: 467-480

Foltyn S. \& GerLing D. 1985: The parasitoids of the aleyrodid Bemisia tabaci in Israel: development, host preference and discrimination of the aphelinid wasp Eretmocerus mundus. Entomol. Exp. Appl. 38: 255-260.

Fransen J.J. 1994: Bemisia tabaci in the Netherlands: Here to stay? Pestic. Sci. 42: 129-134.

Gennadius P. 1889: Disease of the tobacco plantations in the Trikonia. The aleurodid of tobacco. Ellenike Ga. 83: 1-3.

GERLING D. 1966: Studies with whitefly parasites of southern California II. Eretmocerus californicus Howard (Hymenoptera: Aphelinidae). Can. Entomol. 98: 1316-1329.

Gerling D. (eds) 1990: Whiteflies: Their Bionomics, Pest Status and Management. Intercept, Andover, $348 \mathrm{pp}$.

GerLing D. \& MAYER R.T. (eds) 1996: Bemisia 1995: Taxonomy, Biology, Damage, Control and Management. Intercept, Andover, $702 \mathrm{pp}$.

Gerling D., Alomar O. \& Arno J. 2001: Biological control of Bemisia using predators and parasitoids. Crop. Prot. 20: 779-799. 
Goolsby J.A., Ciomperlik M.A., Legaspi B.C. , Lepaspi J.C. \& WeNDEL L.E. 1998: Laboratory and field evaluation of exotic parasitoids of Bemisia tabaci (Gennadius) (Biotype "B") (Homoptera: Aleyrodidae) in the lower Rio Grande valley of Texas. Biol. Control 12: 127-135.

Greenberg S.M., Legaspi B.C. Jr., Jones W.A. \& EnKegaArd, A. 2000: Temperature-dependent life history of Eretmocerus eremicus (Hymenoptera: Aphelinidae) on two whitefly hosts (Homoptera: Aleyrodidae). Environ. Entomol. 29: 851-860.

Greenberg S.M., Jones W.A. \& Liu T.-X. 2002: Interactions among two species of Eretmocerus (Hymenoptera: Aphelinidae), two species of whiteflies (Homoptera: Aleyrodidae), and tomato. Environ. Entomol. 31: 397-402.

Headrick D.H., Bellows T.S. \& Perring T.M. 1999: Development and reproduction of a population of Eretmocerus eremicus (Hymenoptera: Aphelinidae) on Bemisia argentifolii (Homoptera: Aleyrodidae). Biol. Control 28: 300-306.

Heinz K.M. \& Parrella M.P. 1994: Poinsettia (Euphorbia pulcherrima Willd. ex Koltz.) cultivar-mediated differences in performance of five natural enemies of Bemisia argentifolii Bellows and Perring, n.sp. (Homoptera; Aleyrodidae). Biol. Control 4: 305-318.

Henter H.J. \& VAN Lenteren J.C. 1996: Variation between laboratory populations in the performance of the parasitoid Encarsia formosa on two host species, Bemisia tabaci and Trialeurodes vaporariorum. Entomol. Exp. Appl. 80: 427-434.

Henter H.J., Brasch K. \& van Lenteren J.C. 1996: Variation between laboratory populations of Encarsia formosa on their parasitization behavior on the host Bemisia tabaci. Entomol. Exp. Appl. 80: 435-441.

HoddLE M.S. \& van Driesche R. 1996: Evaluation of Encarsia formosa (Hymenoptera: Aphelinidae) to control Bemisia argentifolii (Homoptera: Aleyrodidae) on poinsettia (Euphorbia pulcherrima): a lifetable analysis. Florida Entomol. 79: 1-12.

Hoddle M.S., van Driesche R. \& SAnderson J.P. 1997: Biological control of Bemisia argentifolii (Homoptera: Aleyrodidae) on poinsettia with inundative release of Encarsia formosa Beltsville strain (Hymenoptera: Aphelinidae): Can parasitoid reproduction augment inundative releases? J. Econ. Entomol. 90: $910-924$.

Hoddle M.S., van Driesche R.G., SAnderson J.P. \& MindenBERG O.P.J.M. 1998: Biological control of Bemisia argentifolii (Homoptera: Aleyrodidae) on poinsettia with inundative release of Eretmocerus eremicus (Hymenoptera: Aphelinidae): do release rate affect parasitism? Bull. Entomol. Res. 88:47-58.

Jones W.A. \& Greenberg S.M. 1998: Suitability of Bemisia argentifolii (Homoptera: Aleyrodidae) instars for parasitoid Eretmocerus mundus (Hymenoptera: Aphelinidae). Environ. Entomol. 27: 1569-1573.

Manzano M. R., van Lenteren J. C. , Cardona C. \& Drost Y. C. 2000: Developmental time, sex ratio and longevity of Amitus fuscipennis MacGown and Nebeker (Hymenoptera: Platygastridae) on the greenhouse whitefly. Biol. Control 18: 94-100.

McAuslane H.J. \& NGuyen R. 1996: Reproductive biology and behavior of a thelytokous species of Eretmocerus (Hymenoptera: Aphelinidae) parasitizing Bemisia argentifolii (Homoptera: Aleyrodidae). Ann. Entomol. Soc. Am. 89: 686-693.

Meekes E.T.M, Fransen J.J \& van Lenteren J.C. 2002: Pathogenecity of Aschersonia spp. against whiteflies Bemisia argentifolii and Trialeurodes vaporariorum. J. Invertebr. Pathol. 81: 1-11.

NAKAMURA S. 1994: Parasitization and life history parameters of Exorista japonica (Diptera: Tachinidae) using the common armyworm Pseudaletia separata (Lepidoptera: Noctuidae) as a host. Appl. Entomol. Zool. 29: 133-140.

NARANJo S.E. 2001: Conservation and evaluation of natural enemies in IPM systems for Bemisia tabaci. Crop Prot. 20: 835-852.

Naranjo S.E. \& Ellsworth P.C. 2001: Challenges and opportunities for pest management of Bemisia tabaci in the new century. Crop Prot. 20: 707.

NGUYen R. \& Hamon A.B. 1994: Citrus blackfly, Aleurocanthus woglumi Ashby (Homoptera: Aleyrodidae). Entomol. Circular Fla. Dept. Agric. \& Cons. Serv. 390: 3.

Palumbo J.C., Horowitz A.R. \& PrabhaKar N. 2001: Insecticidal control and resistance management for Bemisia tabaci. Crop Prot. 20: 739-765.

Perring T.M. 2001: The Bemisia tabaci species complex. Crop Prot. 20: 725-737.

Powell D.A. \& Bellows T.S.Jr. 1992: Development and reproduction of two populations of Eretmocerus species (Hymenoptera: Aphelinidae) on Bemisia tabaci (Homoptera: Aleyrodidae). Environ. Entomol. 21: 651-658.

PrICE J.F. 1987: Controlling a new pest. Greenhouse Grower 5: 70-73.

Sharaf N. \& Batta Y. 1985: Effect of some factors on the relationship between the whitefly Bemisia tabaci Genn. (Homopt.: Aleyrodidea) and the parasitoid Eretmocerus mundus Mercet (Hymenopt.: Aphelinidae). J. Appl. Entomol. 99: $267-276$.

SOler Gamborena R. 2003: Performance of Eretmocerus eremicus (Hymenoptera: Aphelinidae) on Trialeurodes vaporariorum (Homoptera: Aleyrodidae): Reproduction, Development and Search Behaviour. MSc thesis, Wageningen University, $54 \mathrm{pp}$.

Szabo P., van Lenteren J.C. \& Huisman P.W.T. 1993: Development time, survival and fecundity of Encarsia formosa on Bemisia tabaci and Trialeurodes vaporariorum. Bull. IOBC/WPRS 16: 173-176.

TAKAGI M. 1985: The reproductive strategy of the gregarious parasitoid, Pteromalus puparum (Hymenoptera: Pteromalidae). 1. Optimal number of eggs in a single host. Oecologia 68: 1-6.

Tawfik M.F.S., Sarhan A.A., Hafez M. \& Awadallah K.T. 1978: Biology of the aphelinid parasite Eretmocerus mundus Mercet. Bull. Soc. Entomol. Egypte 62: 33-48.

Thompson C.R., CoRnell J.A. \& SAILoR R.I. 1987: Interaction of parasites and a hyperparasite in biological control of citrus blackfly, Aleurocanthus woglumi (Homoptera: Aleurodidae), in Florida. Environ. Entomol. 16: 140-144.

VAN LENTEREN J.C. 2000: A greenhouse without pesticides: fact of fantasy? Crop Prot. 19: 375-384.

VAN LENTEREN J.C. \& BRAsCh K. 1994: Variation in acceptance and parasitization of Bemisia tabaci by Encarsia formosa. Bull. IOBC/WPRS 17: 96-103.

VAN LENTEREN J.C. \& NoLDUS L.P.P.J. 1990: Whitefly plant relationships: behavioural and ecological aspects. In:. Gerling D. (ed.): Whiteflies: their Bionomics, Pest Status and Management. Intercept, Andover, pp. 47-98.

VAn Lenteren J.C. \& Woets J. 1988: Biological and integrated pest control in greenhouses. Annu. Rev. Entomol. 33: 239-269.

van Lenteren J.C., van Roermund H.J.W. \& SÜtTERLin S. 1996: Biological control of greenhouse whitefly (Trialeurodes vaporariorum): how does it work? Biol. Control 6: 1-10.

van Lenteren J.C., Drost Y.C., van Roermund H.J.W. \& Posthuma-Doodeman C.J.A.M. 1997: Aphelinid parasitoids as sustainable biological control agents in greenhouses. $J$. Appl. Entomol. 121: 473-485. 
van Lenteren J.C., van Vianen A., Gast H.F.\& Kortenhoff A. 1987: The parasite-host relationship between Encarsia formosa Gahan (Hymenoptera: Aphelinidae) and Trialeurodes vaporariorum (Westwood) (Homoptera: Aleyrodidae). XVI. Food effects on oogenesis, oviposition, life-span and fecundity of Encarsia formosa and other hymenopterous parasites. J. Appl. Entomol. 103: 69-84.

Vet L.E.M. \& van Lenteren J.C. 1981: The parasite-host relationship between Encarsia formosa Gahan (Hymenoptera:
Aphelinidae) and Trialeurodes vaporariorum (Westwood) (Homoptera: Aleyrodidae). X. A comparison of three Encarsia spp. and one Eretmocerus sp. to estimate their potentialities in controlling whitefly on tomatoes in greenhouse with a low temperature regime. J. Appl. Entomol. 91: 327-348.

Received June 5, 2003; revised August 11, 2003; accepted November 3, 2003 